TIERS Information Technology Journal

Vol.2, No.1, Juni 2021, pp. 37 43

ISSN: 2723-4541 / E-ISSN: 2723-4533

DOI: $10.38043 /$ tiers.v2i 2.3310

\title{
Prototyping PCB Menggunakan Computer-Aided Design
}

\author{
I Wayan Sukadana ${ }^{1}$, I Made Pande Darma Yuda ${ }^{2}$ \\ ${ }^{12}$ Program Studi Teknologi Informasi, Universitas Pendidikan Nasional, Bali
}

\begin{abstract}
The increasing and growing development of technology can make it easier for creative people to design systems and electronics. In electronics there are components that are very important to support the components and provide a connecting line between components, namely pcb boards. Before the CAD technology to make PCB the developers of Smart System / Internet of Things technology still make PCB in a manual way but over time and with the development of technology now make PCB is easy with the computer-aided design (CAD). The initial technique of an IoT / Smart System developer to create a PCB is still by creating a component layout and adjusting the scale to the components after that it is only the process of drawing paths using permanent markers that are made in such a way as what has been described first just done the eatching process. After the CAD technology there are many changes at each stage of its creation so there is no need to draw the layout of the components and adjust the skla with cad it has all been automatically determined. In the manufacture of PCB with CAD can display the silk or front image so that the silk part can be taped to the top of the PCB to make it easier to determine the place of the component. The manufacturing process is also more efficient and more regular by using CAD than making manually so that with the Computer-Aided Design (CAD) is very helpful in the process of making PCB design.
\end{abstract}

Keywords: Printed circuit Board (PCB), Computer Aided Design (CAD)

\section{ABSTRAK}

Perkembangan Teknologi yang semakin meningkat dan berkembang dapat memudahkan orang-orang yang kreatif dalam merancang system dan elektronik. Pada elektronik terdapat komponen yang sangat penting untuk menunjang komponen dan memberikan jalur penghubung antarkomponen yaitu papan PCB. Sebelum adanya technology CAD untuk membuat PCB para pengembang technology Smart System/Internet of Things masih membuat PCB dengan cara manual namun seiring berjalannya waktu dan dengan berkembangnya teknologi sekarang membuat PCB sudah mudah dengan a danya Computer-Aided Design (CAD). Teknik awal seorang pengembang IoT/Smart System membuat PCB yaitu masih dengan cara membuat tata letak komponen dan menyesuaikan skala dengan komponennya setelah itu baru proses menggambar jalur menggunakan spidol permanen yang dibuat sedemikian rupa dengan apa yang telah digambarkan terlebih dahulu baru dilakukannya proses eatching. Setelah adanya technology CAD terdapat banyak perubahan disetiap tahap pembuatannya jadi tidak perlu mengga mbar tata letak komponen dan menyesuaikan sklanya dengan CAD itu semua sudah otomatis di tentukan. Pada pembuatan PCB dengan CAD bisa menampilkan bagian silk atau gambar bagian depan sehingga bagian silk tersebut bisa ditempel ke bagian atas PCB untuk memudahkan menentukan tempat komponennya. Proses pembuatannya juga lebih efisien dan lebih teratur dengan menggunakan CAD dari pada membuat secara manual sehingga dengan adanya Computer-Aided Design (CAD) sangat membantu dalam proses pembuatan desain PCB.

Kata kunci: Printed circuit Board (PCB), Computer Aided Design (CAD)

\section{Info Artikel}

\begin{tabular}{lll} 
Diterima Redaksi & $:$ & $01-11-2021$ \\
Selesai Revisi & $:$ & $01-12-2021$ \\
Diterbitkan Online & $:$ & $30-12-2021$ \\
\hline
\end{tabular}

This is an open access article under the CC BY-SA license.

Penulis Korespondensi:

I Made Pande Darma Yuda

Program Studi Teknologi Informasi,

Universitas Pendidikan Na sional (UNDIKNAS) Denpasar, 
Jalan Sidakarya No. 39 Denpasar, Kode Pos 80224..

Email: kadekpande34@gmail.com

\section{PENDAHULUAN}

PCB merupakan komponen utama yang paling penting di bagian elektronik. PCB yang artinya Printed circuit Board yang digunakan sebagai papan untuk pembuatan jalur listri pada rangkaian elektronik yang menghubungkan komponen elektronika yang digunakan[1]. Perkembangan teknologi saat ini yang semakin meningkat dan berkembang yang membuat para pengembang smart system/Internet of Thing terus membuat system baru atau alat baru, maka kebutuhan akan alat-alat elektronik juga terus meningkat dan terus ada pengembangan di setiap komponen[2]. Pada proses pembuatan PCB terdapat beberapa hal yang harus dilakuakn mulai dari pemilihan papan PCB dengan ketebanan tembaganya harus mampu memenuhitegangan pada a lat yang a kan dibuat, perancangan layout supa ya pemasangan komponen tidak a da yang terhalang oleh komponen lainnya, pengga mbaran layout supaya tidak a da jalur yang menumpukyang menga kiba tkan konslet, penempelan layout ke papan PCB dan pelarutan PCB yang bagian tembaganya perlu di hilangkan dengan proses yang disebut dengan Etching[3].

Pada pembuatan PCB sebelumnya para pengembang system IoT yang pertama masih menggambar komponen dikertas dan menyesuaikan skala denagn ukuran a slinya kemudian baru melakukan penggambaran jalur penghubung antar komponen elektronika dengan menggunakan spidol permanen pada la pisan tembaga di PCB [4]. Karena pembuatan jalurnya dengan sepidol jadi harus benar-benar teliti dalam pembuatan jalumya supaya tidak terlalu mepet yang bisa mengakibatkan terjadinya konslet dan supaya tidak menumpuk saat melakukan pemasangan komponennya[5].

CAD merupakan sebuah technology yang biasa disebut Computer Aided Design. CAD ini biasa digunakan untuk mendisain bagian suatu produk yang berupa 2D[6]. Fungsi dari CAD ini adalah untuk mengubah rangkaian komponen elektronika yang dibuat CAE menjadi bentuk PCB [7]. Proses ini adalah kelanjutan dari tahap netlist dan daftar komponen sehingga bagian ini merupakan prose s desain layout PCB. Technology CAD ini sangat memudahkan dalam proses pembuatan PCB karena tidak perlu melakukan pengukuran komponan yang akan digunakan karena ketika menginport komponen dari software eagle sudah sesuai dengan ukuran a slinya.

\section{METODE PENELITIAN}

Pada proses pembuat desain PCB pada da sarnya terdapat dua cara yang dapat digunakan yaitu secara manualdan dengan cara mengguakan Computer-Aided Design (CAD).

\subsection{Pembuatan Desain PCB Secara Manual}

Proses pembuatan PCB secara manual pada tahap awal yang lakukan yaitu mengukur ukuran komponen yang akan digunakan kemudian mengga mbar aturan letak komponen-komponen elektronika sesuai bentuk yang kita inginkan dan memperhitungkan jarak antarkomponen supaya tidak terjadi penumpukan saat proses pemasangan.

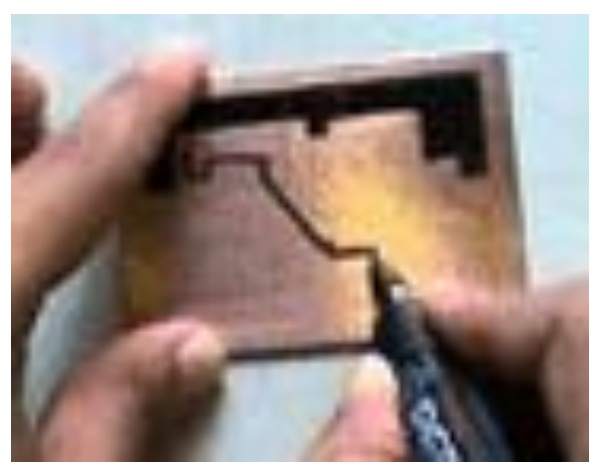

Gambar.1,Proses pembuatan jalurkomponen dengan spidol

Siapkan papan PCB yang a kan digunakan kemudian amplas bagian tembaganya menggunakan amplas halus sampaibersih supaya tinta spidolmenempel secara bagus. Setelah itu lakukan proses menggambarjalur penghubung antar komponen elektronika sesuai dengan tatanan yang sudah dibuat dengan menggunakan spidol permanent seperti ga mbar.1 diatas, pastikan jalur yang telah dibuat sesuai dengan jalur yang mana seharusnya terhubung dan yang mana tidak terhubung supaya tidak terjadinya konslet. Setelah semua sudah terhubung 
dengan benar, maka selanjutnya lakukan pemotongan PCB sesuai dengan ukuran yang telah ditentukan sebelumnya supaya pada saat etching lebih efisien karena tidak terlalu banyak mela rutkan tembaga.

\subsection{Pembuatan Desain PCB Menggunakan Computer-Aided Design (CAD)}

Pada proses pembuatan PCB menggunakan CAD lebih efisien, lebih rapi, dan lebih akurat dari pada membuat PCB secara manual, dengan CAD ukuran jalur penghubung antarkomponen bisa ditentukan sesuai dengan tegangan yang dihasilkan. Proses pembuatan PCB dengan CAD seperti tahapan berikut.

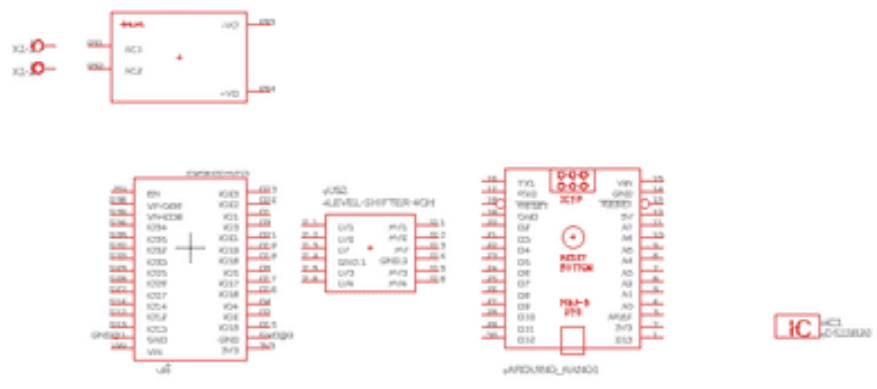

Gambar.2, Menginport komponen elektronika

Gambar diatas merupakan proses menginput komponen elektronika yang akan digunakan pada sistem Internet of Things yang akan dibuat dengan menggunakan software Eagle. Terdapat beberapa komponen yang digunakan seperti gambar 2. diatas yang memiliki fungsinya masing-masing, setelah itu melakukan proses menentukan tata letak komponen supa ya tidak berbenturan a tau menumpuk sisi pinggirann ya dan menentukan bagian mana yang diha dapkan keluar karena akan a da kabel atau colokan yang akan diguakan.

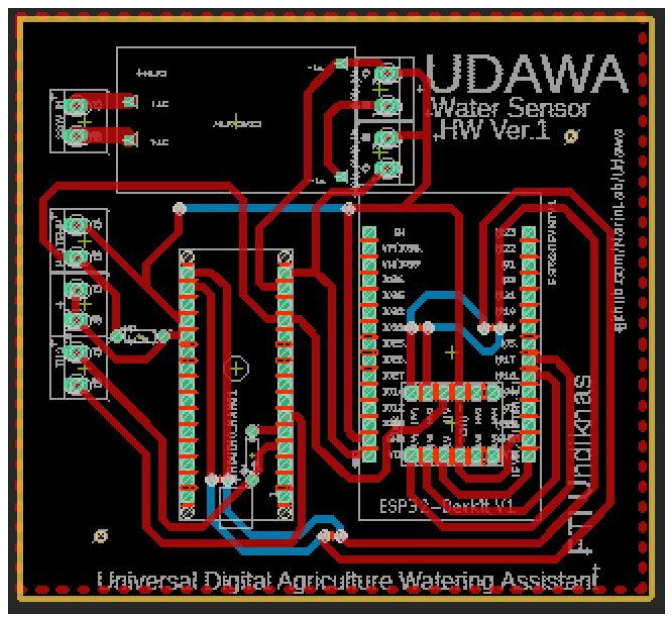

Gambar.3, Proses Routing

Gambar diatas merupakan proses routing PCB yaitu membuatkan jalur penghubung komponenkomponen elekronika supaya komponen tersebut bisa saling berhubungan dengan baik sesuai dengan rancangan yang dibuat. Ja lur tersebut tidak boleh ada yang tertumpuk kecualimemangja lurnya sama. Ketika terdapat jalur yang tertumpuk maka solusi yang bisa digunakan yaitu dengan menggunakan bottom layer seperti gambar.3 jalur yang berwarna biru tersebut adalah jalur yang dibuat menggunakan bottom layer jadi jalurnya itu bera da dibagian bawah papan PCB. Ketika papan PCB yang diguakan hanya terda pat satu lapisan tembaga maka bisa digantikan dengan kabelbatangan yang berukuan kecil. 


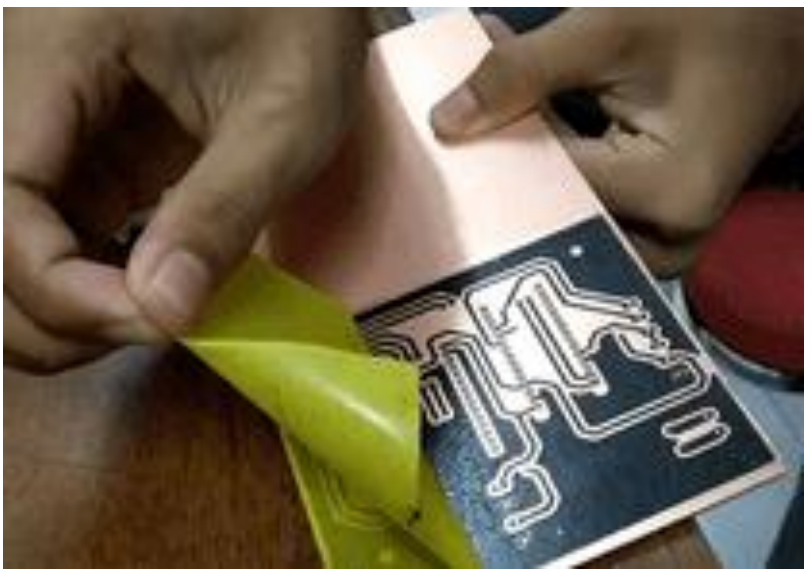

Gambar.4, Proses Toner Transfer Menggunakan PCB Transfer Paper

Berbeda ketika membuat PCB dengan cara manual yaitu penggambar jalurnya dengan sepidol gambar.4 diatas adalah proses menempelkan hasil desain dengan CAD ke bagian tembaga pada papan PCB menggunakan kertas transfer paper, sebelum ditempelkan ke PCB hasil disain harus diprint dahulu menggunkan kertas transfer pa per dan printer la sterjet a tau printer yang tintanya serbuk. Proses penempelannya menggunakan minyak kayu putih yang dibalurkan ke bagian tembaga supaya tinta yang dikertas mau menempel ke tembaga kemudian dipanaskan dengan menggunakan setrika sampai tintanya menempel ke tembaga setelah itu baru dimasukan ke air untuk di lepaskan bagian kertasnya jika ada bagian tinta yang ikut terangkat, maka perlu dilapisi kembali dengan menggunakan spidol permanen kemudian dipotong sesuai ukurannya.

\subsection{Proses Etching}

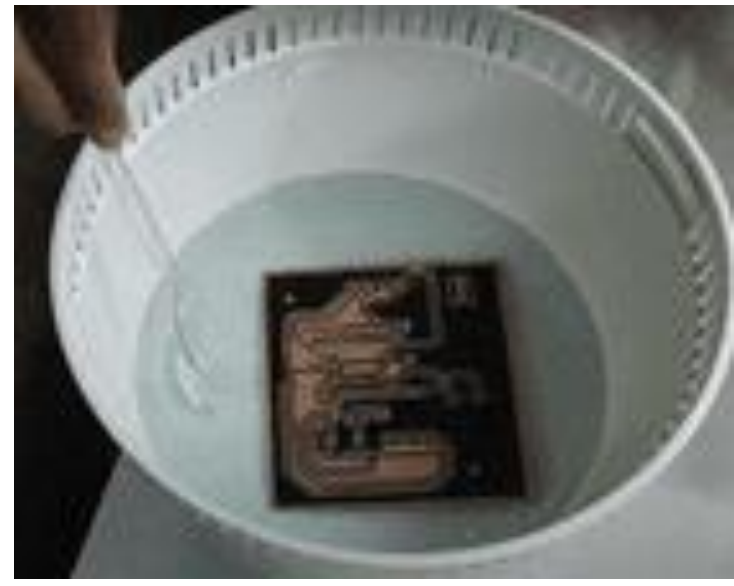

Gambar.5, Proses Etching

Etching adalah proses pengkikisan a tau penyubliman lapisan tembaga yang terdapat pada papan PCB menggunakan Larutan Etching dan hcl h2o o2, bagian tembaga yang dihilangkan adalah bagian yang tidak terlapisi oleh tinta a tau spisol. Proses etching ini dilakukan dengan mencampurkan 50\% air biasa dengan 50\% La rutan Etching dan hclh2o o2 dan harus menggunakan wadah pla stik seperti ga mbar.5 dia tas. Caranya dengan memasukannya kemudian digoyang-goyangkan selang beberapa menit diangkat terus dicelupkan lagi sampai temba ganya benar-benar habis, ka lau dira sa lama atau larutannya kurang pekat bisa dita mbahkan la gi Larutan Etching dan hel h2o o2.

\section{HASIL DAN PEMBAHASAN}

Hasil dari pembuatan PCB dengan cara manual maupun menggunakan CAD

\subsection{Tampilan}

TIERS Information Technology Journal, Vol. 2, No. 2, Desember 2021:37-43 


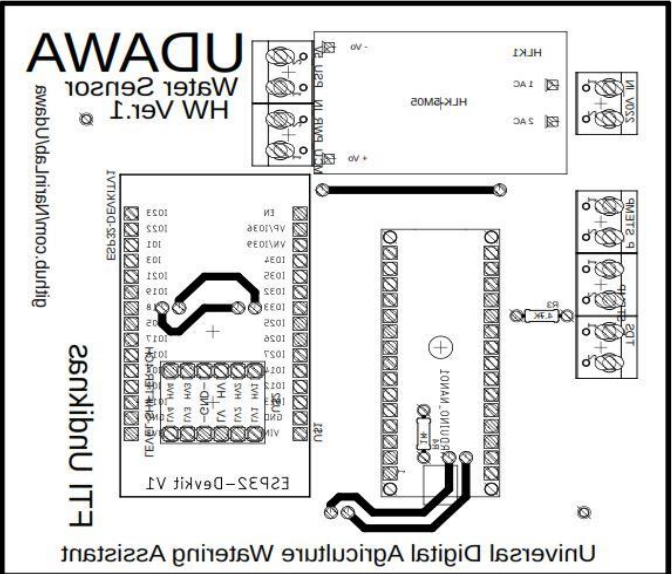

Gambar.6, Tampilan Silk

Dari segi tampilan terlihat dengan jelas kalau menggunakan CAD jauh lebih rapi, lebih aman dan tentunya lebih presisi akan ukuran komponen elektronika sehingga memudahkan dalam pemasangan komponennya. Sepetrti yang terdapat pada gambar.6 diatas adalah bagian silk yang bisa dicetak kemudian ditempelkan pada bagian atas PCB sehingga memudahkan kita untuk mengetahui tempat-tempat komponennya.

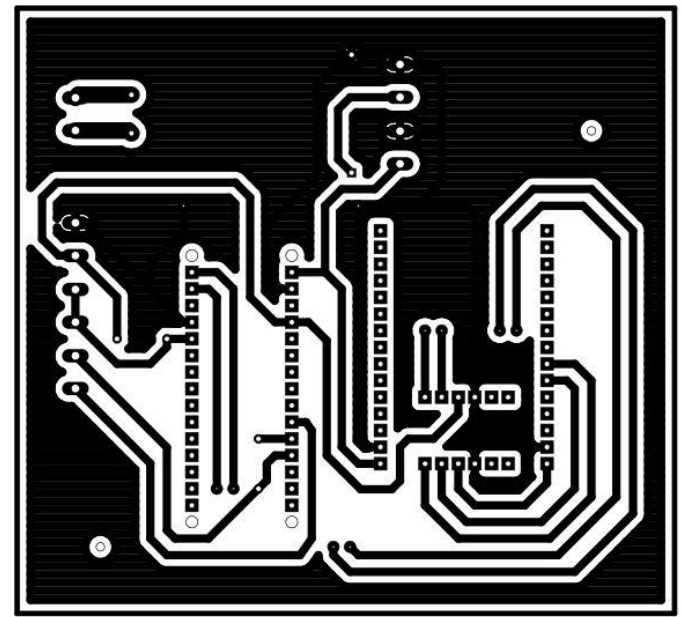

Gambar.7, Bagian Jalur PCB yang sudah di Ratsnest

Setelah selesai mendesain dan routing selanjutnya dilakukan proses Ratsnest. Proses ratsnest ini berfungsi untuk merapikanjalur sehingga tidak terliahat berantakan dan membingungkan dapat dilihat ha silnya seperti pada gambar.7, selain itu lebih efisien pada saat etching karena tidak terlalu banyak melarutkan tembaga.

\subsection{Kualitas}




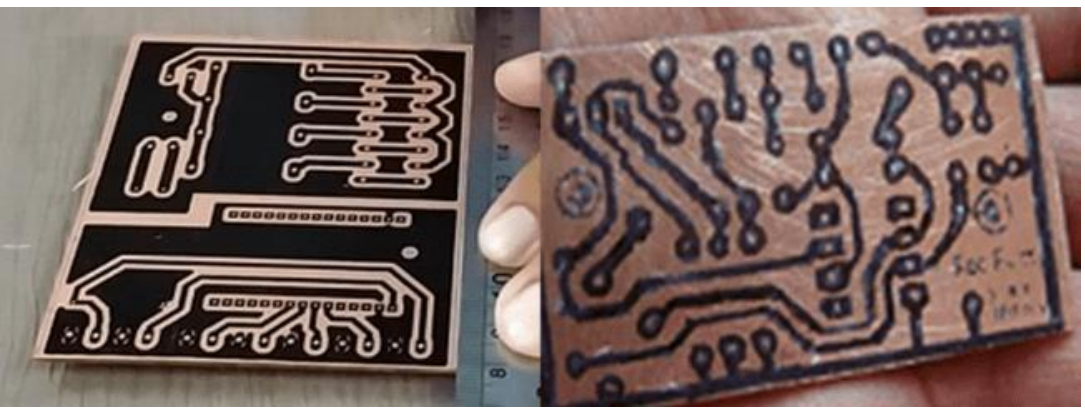

Gambar.8, Tampilan pembuatan PCB secara manualdan dengan CAD

Dari segi kualitas perbedaan PCB yang dibuat secara manual dengan menggunakan CAD terlihat sangat jelas, hasil yang menggunakan $\mathrm{CAD}$ lebih rapi dan lebih terstruktur jalur penghubung antar komponennya. Ketika melakukan etching juga lebih efisien karena setelah diselesaikan dengan Ratsnest semua yang terhubung dengan ground (GND) akan diblock hitam jadi tidak terlalu banyak menghilangkan bagian tembaganya.

\subsection{Keamanan}

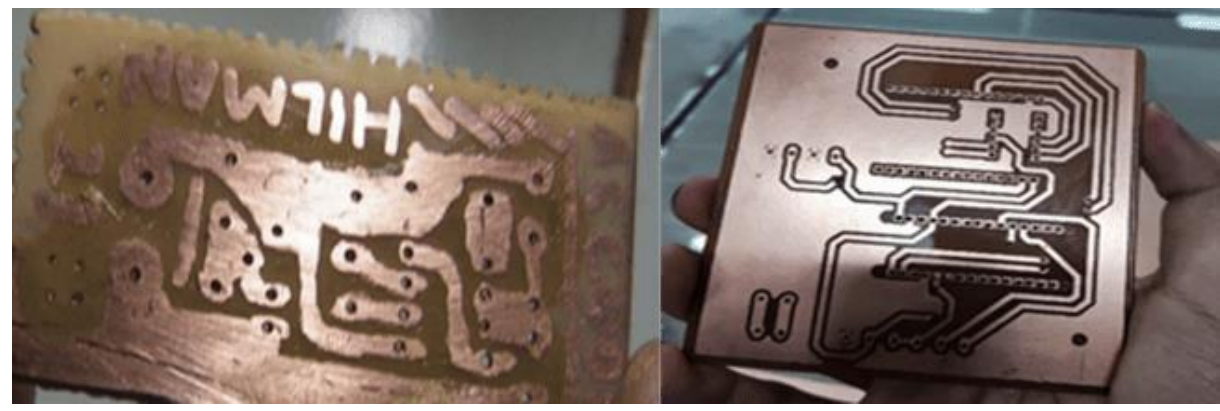

Gambar.9, Hasil akhir pembuatan PCB secara manual dan dengan CAD

Keamanan PCB yang dibuat dengan CAD lebih anam digunakan karena jarak antar komponen sudah diatur dengan baik dan ukuran jalurnya juga sudah diatur sesuai dengan tegangannya berbeda dengan hasil yang dibuat secara manualjarak antara jalur penghubung antarkomponen elektronika masih tidak te ratur dan ada yang terlalu mepet, kemungkinan itu bisa mengakibatkan konslet dan komponen akan hangus.

\section{KESIMPULAN}

Berdasarkan hasil pembahasan diatas dapat disimpulkan bahwa proses pembuatan PCB menggunakan Computer-Aided Design (CAD) dibandingkan dengan cara manual terdapat banyak kelebihan yang didapat saat pembuatannya begitu juga hasilnya pun jauh lebih bagus dengan menggunakan CAD. Dari proses mendisain yang tinggal memasukan komponen yang digunakan kemudian menen tukan tata letaknya dan dilanjutkan dengan proses routing yang menghubungkan antar komponen. Dari segi tampilan juga hasilnya lebih rapi dan lebih presisi pada lubang untuk memasukan komponen, ketebalan jalur penghubung juga bisa ditentukan sesuai dengan tegangan yang melalui jalur tersebut.

\section{DAFTAR RUJUKAN}

[1] Mukhofidhoh and N. Kholis, "Rancang Bangun Mesin Pengebor PCB Mini Otomatis Berbasis Arduino UNO," J. Tek. Elektro, vol. 7, no. 1, pp. 9-16, 2018.

[2] N. D. Ummiati Rahmah, Edy Sabara, "Pengembangan Trainer Microcontroller Berbasis Internet of Things (IoT) Pada Mata Kuliah Microcontroller dan Interface Di Jurusan Pendidikan Teknik Elektronika Fakultas Teknik Universitas Negeri Makasar," J. ETC, vol. 14, 2020.

[3] N. Brillianta Akbar, "Perancangan mesin pencetak jalur pcb menggunakan sinar uv berbasis arduino uno," 2017.

[4] Z. B. Anwar, A. Widodo, N. Kholis, and Nurhayati, "Sistem Monitoring Pasien Isolasi Mandiri Covid-19 Berbasis Internet of Things,” J. Tek. Elektro, vol. 10, no. 3, pp. 689-697, 2021. 
[5] A. Susatyo and C. Bariyah, "Perancangan Fasilitas Kerja yang Ergonomis pada Proses Pelarutan," Jisi J. Integr. Sist. Ind., vol. 3, no. 1, pp. 7-14, 2016.

[6] R. Sholikhah and S. Nurmasitah, "PELATIHAN PEMBUATAN POLA BUSANA DIGITAL BERBASIS CAD DENGAN SOFTWARE RICHPEACE PADA GURU-GURU SMK TATA BUSANA,”pp. 1-7.

[7] S. Sunar and S. Subagiyo, "Peningkatan Keaktifan dan Ketrampilan Membuat PCB Kelas XII TAV SMK Negeri 1 Semarang," Edu Elektr. J., vol. 9, no. 2, pp. 55-60, 2020, [Online]. Available: https://journal.unnes.ac.id/sju/index.php/eduel/article/view/37973. 